\title{
An Unusual Gastric Subepithelial Lesion: Expect the Not so Expectable
}

\author{
Rui Mendo ${ }^{a}$ Rita Barosa ${ }^{a}$ Pedro Pinto Marques ${ }^{b}$ Catarina Albuquerque \\ Cristina Maia Santos ${ }^{\mathrm{d}}$ \\ aDepartment of Gastroenterology, Centro Hospitalar Lisboa Ocidental, Hospital de Egas Moniz, Lisbon, Portugal; \\ ${ }^{\mathrm{b}}$ Department of Gastroenterology, Hospital Garcia de Orta, Almada, Portugal; ' Department of Pathology, \\ Centro Hospitalar Lisboa Ocidental, Hospital de Egas Moniz, Lisbon, Portugal; d Department of Surgery, Centro \\ Hospitalar Lisboa Ocidental, Hospital de Egas Moniz, Lisbon, Portugal
}

\section{Keywords}

Glomus tumor · Gastric subepithelial lesion

\section{Uma lesão subepithelial gástrica incomum: esperar o inesperado}

\section{Palavras Chave}

Tumor glómico · Lesão subepithelial gástrica

A 37-year-old leucodermic woman with no relevant past history presented with 1-month history of new-onset epigastric pain and bloating. She denied any other symptoms. She underwent an esophagogastroduodenoscopy that revealed a $25-\mathrm{mm}$ subepithelial lesion in the gastric antrum (Fig. 1). Tunnel biopsies were done and were unrevealing. She underwent an endoscopic ultrasound (EUS) that showed a 25 -mm hypoechogenic subepithelial lesion originating in the muscularis propria (Fig. 2). EUS-guided fine-needle aspiration (FNA) with a $25-\mathrm{G}$ needle (Boston Scientific $\left.{ }^{\circledR}\right)$ was performed $(2 \times$ passes using suction technique), revealing cell nests without atypia, that were focally positive for smooth-muscle

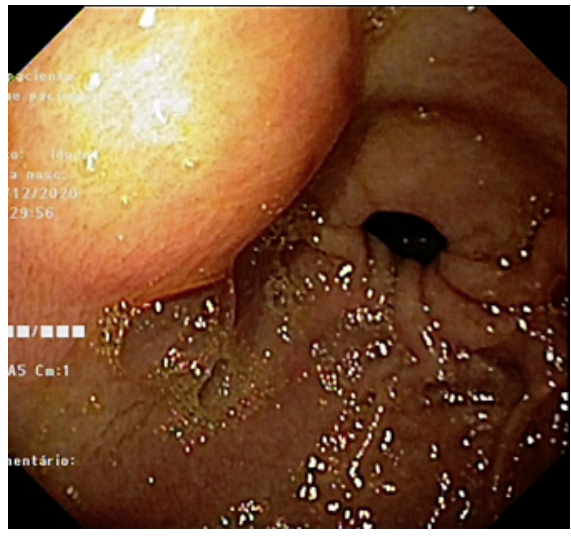

Fig. 1. Esophagogastroduodenoscopy revealed a 25-mm subepithelial gastric lesion in the gastric antrum.

actin and synaptophysin, and negative for chromogranin and CD117. KIT and PDGFRA mutations were also negative. Unfortunately, the sample was inadequate for further study. A staging CT was performed excluding distant metastasis. Since investigations thus far were inadequate to exclude a malignant process, she underwent laparoscopic-wedge gastrectomy. Histopathology revealed a solid, epithelioid, and richly vascular tumor

\section{(c) 2021 Sociedade Portuguesa de Gastrenterologia} Published by S. Karger AG, Basel

This is an Open Access article licensed under the Creative Commons Attribution-NonCommercial-4.0 International License (CC BY-NC) (http://www.karger.com/Services/OpenAccessLicense), applicable to the online version of the article only. Usage and distribution for commercial purposes requires written permission.
Correspondence to:

Rui Mendo, mendorui@gmail.com 


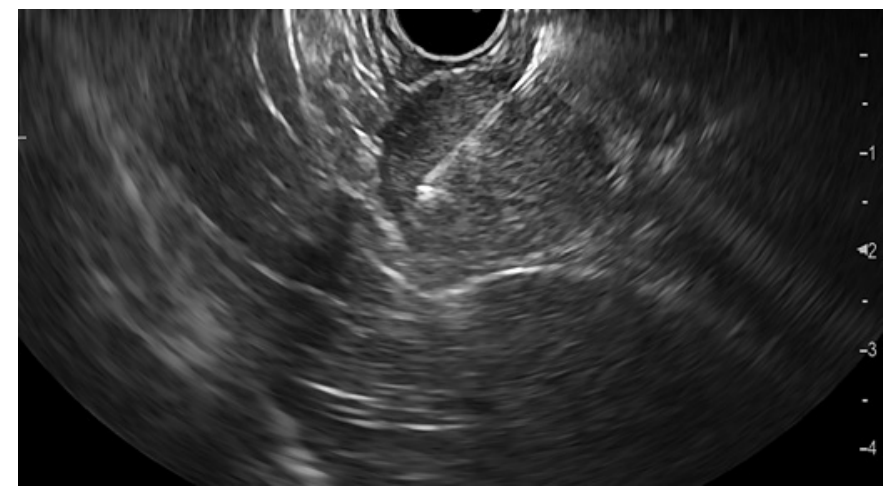

Fig. 2. EUS showing a 25-mm hypoechogenic subepithelial gastric lesion originating in the muscularis propria.

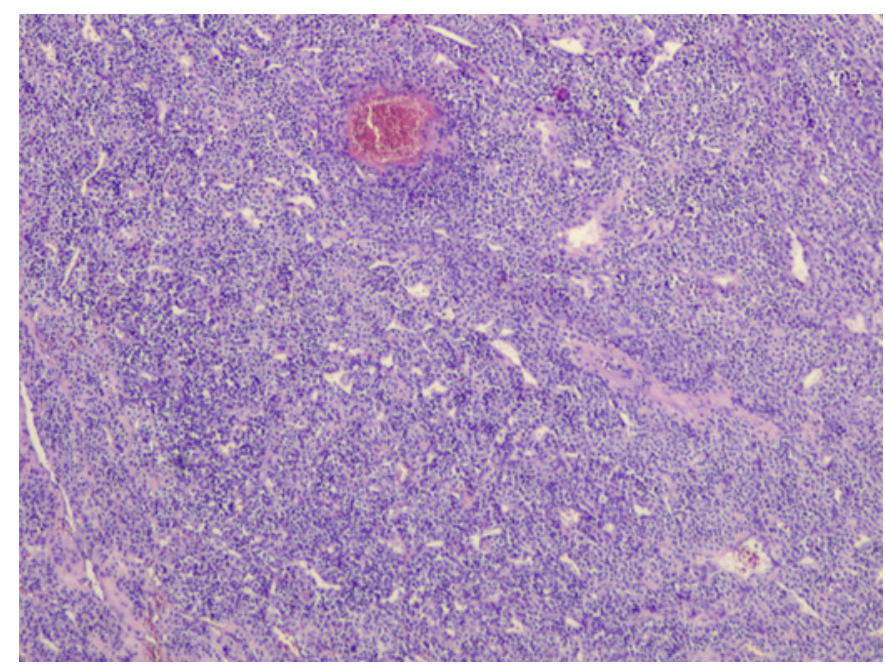

Fig. 3. Histopathology revealing a solid, epithelioid, and richly vascular tumor without atypia.

without cellular atypia (Fig. 3). Immunohistochemistry was similar to that previously performed and complemented with positive calponin (Fig. 4) and negative cytokeratin AE1/AE3 (Fig. 5), making the diagnosis of a glomus tumor.

Glomus tumors are rare mesenchymal neoplasms that originate in modified smooth-muscle cells [1-3]. Despite being highly vascularized, they are most often benign [3]. They are frequently found in the skin and subcutaneous tissue, although they can also be located in the gastrointestinal tract, most commonly in the stomach $[2,3]$. Gastric glomus tumors are usually located in the antrum $[2,3]$. Clinical symptoms are nonspecific, ranging from dyspepsia to gastrointestinal bleeding [3]. Endoscopically, they appear as a smooth

An Unusual Gastric Subepithelial Lesion

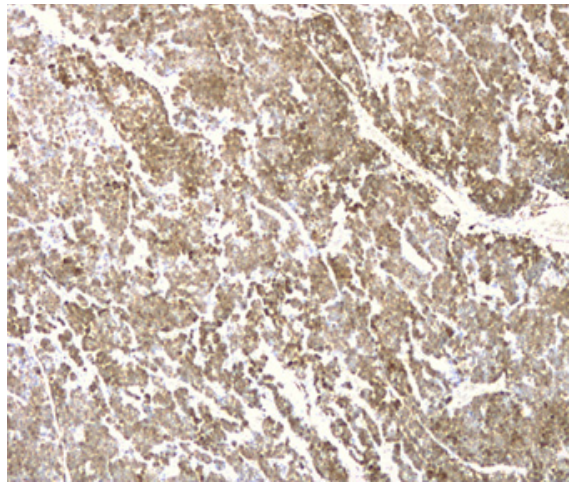

Fig. 4. Positive immunohistochemistry for calponin.

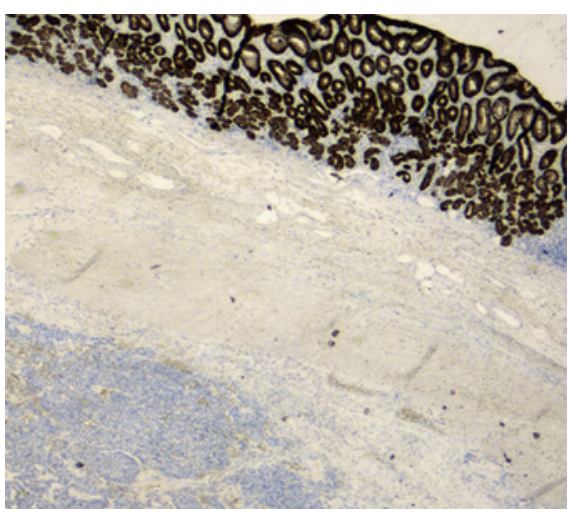

Fig. 5. Negative immunohistochemistry for cytokeratin AE1/AE3.

submucosal lesion, usually $2-3 \mathrm{~cm}$ in size, and present as an ulcerated submucosal lesion in roughly $45 \%$ of cases [3]. On EUS, they typically originate from the muscularis propria (4th echo layer) but can also be found in the submucosal or mucosal layers [1]. Additionally, they can present either as hyperechoic or hypoechoic, usually have internal hyperechoic foci, and present a prominent Doppler signal consistent with the vascular nature of these tumors $[1,2]$. However, it can be difficult to distinguish them from other subepithelial lesions (e.g., gastrointestinal stromal and neuroendocrine tumors) since they do not exhibit specific distinguishing features on EUS [2]. EUS-FNA is an effective method to obtain cytological specimens of gastric submucosal neoplasms, allowing for an adequate histopathological evaluation when using the cell-block technique. However, to ensure an adequate diagnosis of a gastric submucosal lesion, it is important to perform an immunohistochemical study on the cell block [4]. Gastric glomus tumors are 
typically positive for actin, calponin, and vimentin, and negative for CD117, CD20, and CD45, chromogranin A, desmin, and S-100 protein, allowing the distinction of these tumors in the differential diagnosis [3]. Since malignant transformation has been described, a complete resection of the lesion is mandatory for definitive treatment $[2,3]$. The surgical approach depends on the location and size of the tumor. Zhang et al. [2] reported an effective endoscopic approach through endoscopic submucosal dissection technique. However, due to its infrequency, there are insufficient data to establish guidelines regarding management, including the need for postoperative surveillance.

This case denotes the diagnostic challenge and the not-so-linear diagnostic evaluation when facing a gastric subepithelial lesion. The key point is that gastroenterologists should be aware of this rare, difficult-to-diagnose, and potentially malignant entity in the differential diagnosis of subepithelial lesions, especially when present in the stomach.

\section{Statement of Ethics}

The authors have no ethical conflicts to disclose. Informed consent was obtained from the patient for the publication of this article.

\section{Conflict of Interest Statement}

The authors have no conflicts of interest.

\section{Funding Sources}

The authors have no funding sources to declare.

\section{Author Contributions}

All authors contributed equally to the conception, analysis, and interpretation of data, as well as drafting and critical revision of the article for important intellectual content. All authors approved the final version of the manuscript.
References
1 Chou KC, Yang CW, Yen HH. Rare gastric glomus tumor causing upper gastrointestinal bleeding, with review of the endoscopic ultrasound features. Endoscopy. 2010;42(Suppl 2):E58-9.

2 Zhang Y, Zhou P, Xu M, Chen W, Li Q, Ji Y, et al. Endoscopic diagnosis and treatment of gastric glomus tumors. Gastrointest Endosc. 2011 Feb;73(2):371-5.
3 Miettinen M, Paal E, Lasota J, Sobin LH. Gastrointestinal glomus tumors: a clinicopathologic, immunohistochemical, and molecular genetic study of 32 cases. Am J Surg Pathol. 2002 Mar;26(3):301-11.

4 Debol SM, Stanley MW, Mallery S, Sawinski E, Bardales RH. Glomus tumor of the stomach: cytologic diagnosis by endoscopic ultrasound-guided fine-needle aspiration. Diagn Cytopathol. 2003 Jun;28(6):316-21. 